\title{
ORIGINAL ARTICLE Island colonisation and the evolutionary rates of body size in insular neonate snakes
}

\begin{abstract}
F Aubret
Island colonisation by animal populations is often associated with dramatic shifts in body size. However, little is known about the rates at which these evolutionary shifts occur, under what precise selective pressures and the putative role played by adaptive plasticity on driving such changes. Isolation time played a significant role in the evolution of body size in island Tiger snake populations, where adaptive phenotypic plasticity followed by genetic assimilation fine-tuned neonate body and head size (hence swallowing performance) to prey size. Here I show that in long isolated islands (>6000 years old) and mainland populations, neonate body mass and snout-vent length are tightly correlated with the average prey body mass available at each site. Regression line equations were used to calculate body size values to match prey size in four recently isolated populations of Tiger snakes. Rates of evolution in body mass and snout-vent length, calculated for seven island snake populations, were significantly correlated with isolation time. Finally, rates of evolution in body mass per generation were significantly correlated with levels of plasticity in head growth rates. This study shows that body size evolution occurs at a faster pace in recently isolated populations and suggests that the level of adaptive plasticity for swallowing abilities may correlate with rates of body mass evolution. I hypothesise that, in the early stages of colonisation, adaptive plasticity and directional selection may combine and generate accelerated evolution towards an 'optimal' phenotype.
\end{abstract}

Heredity (2015) 115, 349-356; doi:10.1038/hdy.2014.65; published online 30 July 2014

\section{INTRODUCTION}

Island colonisation by animal populations is often associated with dramatic shifts in body size (Darwin, 1845; Case, 1978; Lomolino, 1985; Meiri, 2007). The high incidence of body size divergence between island and mainland populations is a reflection of (1) the conditions (and hence, selective pressures) that often differ tremendously from those experienced by mainland conspecifics; (2) small initial population sizes that facilitate founder effects and rapid shifts in allele frequency; and (3) lack of gene flow with the source area that allows the isolated population to follow a unique evolutionary trajectory (Grant, 1999; Gavrilets and Vose, 2005; Losos and Ricklefs, 2009). Although there have been tremendous efforts to produce a unified theory of body size evolution on islands (that is, island rule-Foster, 1964; Boback, 2003; Meiri, 2007; Meiri et al., 2006, 2008; Aubret, 2012), very few comprehensive studies have succeeded at precisely identifying body size evolutionary drivers and quantifying the rates at which such evolutionary shifts may occur, especially over relatively short time scales (but see Grant and Grant, 2006; Herrel et al., 2008; Garcia-Porta and Ord, 2013). Body size shifts were nevertheless shown to occur rapidly (that is, from a few decades up to several thousands of years) following colonisation in mammals (Millien, 2006), birds (Mathys and Lockwood, 2011) and reptiles (Aubret and Shine, 2007; Herrel et al., 2008). Further, although many forms of plastic responses, including altered behaviours, feeding strategies and defence mechanisms, were invoked in the successful colonisation of new environments (including islands; Ehrlich, 1989; Stearns, 1989; Via et al., 1995; Holway and Suarez, 1999; Pigliucci and
Murren, 2003; West-Eberhard, 2003; Aubret et al., 2004a, b; Yeh and Price, 2004; Fitzpatrick, 2012), the idea that adaptive plasticity may also alter rates of evolution remains very much debated, perhaps because empirical support is scarce (Hinton and Nowlan, 1987; Ancel, 2000; Price et al., 2003; Yeh and Price, 2004; Borenstein et al., 2006; Anderson et al., 2012).

Deciphering the initial evolutionary stages of island colonisation has been the subject of passionate debate over the past decades, where the potential role played by phenotypic plasticity in the early stages of colonisation has been widely recognised (Stearns, 1989; Via et al., 1995; Schlichting and Pigliucci, 1998; Pigliucci and Murren, 2003). Once the new population is established, and if the new conditions remain consistent from one generation to the next, evolutionary theory predicts the loss of plasticity and the evolution of a canalised phenotype (that is, genetic assimilation; Waddington, 1961; Schlichting and Pigliucci, 1998; West-Eberhard, 2003); that is because adaptive plastic responses are both costly and limited (that is, plastic phenotypes are sub-optimal by definition; Behera, 1994; Mayley, 1996; Relyea, 2002; Steinger et al., 2003; Snell-Rood et al., 2010). Although the potential importance of genetic assimilation to evolutionary changes in founder populations has been theoretically demonstrated (Behera, 1994; Rollo, 1994; Mayley, 1996; Schlichting and Pigliucci, 1998; Pigliucci and Murren, 2003; Price et al., 2003; West-Eberhard, 2003; Schlichting, 2004; Badyaev, 2005; Lande, 2009), empirical evidence on this topic is rare. Perhaps for this very reason, it was suggested that genetic assimilation only has a minor role in evolution (de Jong, 2005). On the other hand, several authors pointed out that 
genetic assimilation may in fact occur on such short timescales that it is difficult to detect except under unusual circumstances (Pigliucci and Murren, 2003; Pigliucci et al., 2006).

Numerous insular Tiger snake populations (Notechis scutatus) exist across southern Australia, a result of historical sea level rises (past 10000 years) as well as recent human introductions (Rawlinson, 1974; Schwaner and Sarre, 1988; Cogger, 2000). Populations of Tiger snakes are characterised by highly divergent mean adult body size across island and mainland populations (Keogh et al., 2005). Although a number of hypotheses have been suggested to explain these rapid body size shifts (that is, competition, predation and sexual selection), natural selection acting to optimise snake body size to available prey size is strongly supported by the correlation between snake size and available prey size (Schwaner, 1985; Shine, 1987; Schwaner and Sarre, 1988, 1990; Aubret, 2012). Recent work suggested that larger prey present on islands have generated selective regimes driving increased body and head size at birth in these gape-limited predators, as well as increased levels of adaptive plasticity in head growth in response to prey size (Ehrlich, 1989; Holway and Suarez, 1999; West-Eberhard, 2003; Aubret et al., 2004a; Aubret and Shine, 2007; Aubret, 2012). Although young snakes from recently isolated populations (that is, $<6000$ years) were experimentally shown to be able to accelerate head growth, and hence swallowing performance, in response to large prey (Aubret and Shine, 2009), snakes from older islands no longer exhibited plasticity in response to prey size but were in turn born larger: the trait had been genetically assimilated (Waddington, 1942, 1953; Pigliucci et al., 2006). Williams Island neonates are, for instance, twice as heavy and 30\% longer on average than typical mainland neonates. Consequently, body size at birth recorded in recently isolated populations ( $<6000$ years) may not reflect an 'optimal' match to prey size (for the purpose of this article, we qualify phenotype as optimal in reference to a theoretical body size that provides the highest fitness value for a given average prey size). In this context, I hypothesised that rates of evolution in body size would be higher in recently isolated snake populations (where phenotypes are yet to reach the optimal value and selective forces are the strongest) compared with long isolated populations (where phenotypes are now nearing or have reached the optimal value). This ecological context offers the opportunity to reveal if adaptive plasticity and genetic assimilation may interact to optimise response to selection in novel environments.

\section{MATERIALS AND METHODS \\ Study animals}

Tiger snakes (N. scutatus) are large venomous elapid snakes broadly distributed across southern and eastern Australia (Cogger, 2000). Over the past 10000 years, rising sea levels fragmented previously continuous populations in southern Australia, submerging the broad coastal plain that had linked eastern and western populations and isolating numerous populations on newly formed islands (Rawlinson, 1974; Schwaner, 1985). Genetic divergence among Tiger snake populations across this extensive range is remarkably low (for example, only $1.4 \%$ between Western Australia and southeastern Australia; Keogh et al., 2005). Within southeastern Australia, the maximum genetic divergence is only $0.38 \%$ between populations of island giants, island dwarves and mainland snakes (Keogh et al., 2005). Island populations are most closely related to conspecific populations from the adjacent mainland, confirming that colonisations were phylogenetically independent events (Scott et al., 2001; Keogh et al., 2005).

Mainland Tiger snakes are semi-aquatic snakes, living in swampy areas and feeding on a wide array of frogs (Crinia spp., Litoria spp., Limnodynastes spp.), skinks (Morethia spp., Ctenotus spp., Cryptoblepharus spp., Hemiergis spp., Christinus spp.), small rodents (Mus spp.) and occasionally fish (Salmo spp.; see
Aubret, 2012 for details). Adult mainland Tiger snakes reach between 78 and $92 \mathrm{~cm}$ snout-vent length and usually weigh no more than $400 \mathrm{~g}$ (Shine, 1987; Schwaner and Sarre, 1990). A thorough study of Tiger snake diets demonstrated that mainland Tiger snakes are ecologically homogeneous with respect to diet (Shine, 1987). On islands containing larger rodents (Rattus spp.), skinks (Egernia spp.) and above all seabird colonies (Puffinus spp., Larus spp., Phalacrocorax spp.), Tiger snakes frequently attain giant size ( $>1.5 \mathrm{~m}$ body length, > 2 kg mass; Worrell, 1963; Schwaner and Sarre, 1988). It was recently shown (Aubret, 2012) that body size shifts also occurred in neonate Tiger snakes, with the occurrence of dwarf (Reevesby Island) and giant neonates (Williams Island, Hopkins Island). Prey size appeared to be the main driver for the evolution of body size at birth in Tiger snakes while adult size variations mostly reflected selective forces acting on earlier life stages (that is, adult size largely correlated with birth size across populations), as well as resource availability during ontogeny (notably prey diversity; Aubret, 2012).

The current study is based on data collected between 2001 and 2010. Nine Tiger snake populations were regularly surveyed during numerous field sessions throughout the years. A total of 72 pregnant females were captured and brought back to the laboratory (University of Western Australia: 2001-2003; University of Sydney: 2006-2008). Capture sites included Carnac Island ( $N=21$ females), Herdsman Lake $(N=22)$ and Joondalup Lake $(N=4)$ in Western Australia; Williams $(N=4)$ and Reevesby $(N=4)$ Islands in South Australia; Trefoil $(N=3)$, Christmas $(N=6)$ and New-Year Islands $(N=4)$ in Tasmania and mainland Tasmania $(N=4)$. A total of 1066 neonates were born and measured in snout-vent length $( \pm 0.1 \mathrm{~cm})$ and body mass $( \pm 0.1 \mathrm{~g})$ within $24 \mathrm{~h}$ (Table 1$)$. Complementary data on Chappell Island neonate snake body size were gathered from published literature (Schwanner and Sarre, 1990). One additional Reevesby Island full litter $(N=18)$ was measured at the South Australian Museum.

Data on prey available to each population and prey body mass $( \pm 0.1 \mathrm{~g})$ were gathered from published literature (Schwaner, 1985; Schwanner and Sarre, 1988, 1990; Robinson et al., 1996; Cogger, 2000; Swain and Jones, 2000; Arena and Wooller, 2003; Wilson and Swan, 2003; Aubret et al., 2004b; Chapple, 2005) and from numerous personal field observations. That is, Tiger snakes frequently regurgitate their meal and/or defecate upon capture as a defence mechanism. Prey identification and size can be made more or less precisely depending on the digestion stage or from the presence of scales, fur or feathers in the faeces. Data on prey available were also gathered from museum collections (South Australian Museum Adelaide, Western Australian Museum Perth, Tasmanian Museum and Art Gallery Hobart). Here, only prey likely to be encountered and consumed by neonate Tiger snakes in their natural environment were focussed on (for full details on methods, see Aubret, 2012). Mean prey size were calculated from all prey types potentially available to young snakes at each site, rather than from just the smallest prey item, as mean prey size may better reflect selection regimes occurring on newly colonised islands (Aubret and Shine, 2010). That is, small prey items may constitute a minute proportion of the prey population, or they may be species (for example, burrowing-type skinks) that are rarely found on open ground. It seems unlikely therefore that young Tiger snakes would encounter such a prey on a regular enough basis for them to constitute a significant portion of the diet. Rather, natural selection may act on young snakes that are large enough at birth to be able to swallow a range of prey that are most common (that is, of average size) as well as on young snakes capable of quickly increasing head size, hence swallowing abilities (via adaptive plasticity) after a number of unsuccessful swallowing attempts. Both of these mechanisms were experimentally reproduced in a previous study (Aubret and Shine, 2010).

\section{Estimating isolation times}

Timing of sea level rise and water depth between islands and mainland (that is, bathymetry) were used to estimate isolation time for each population: Williams Island and Chappell Island (9100 years ago; Thom and Chappell, 1975; Belperio et al., 1983; Robinson et al., 1996; Brothers et al., 2001); Christmas Island and New Year Island (6000 years ago; Lambeck and Chappell, 2001); and Reevesby Island (7700 years ago; Robinson et al., 1996). Carnac Island Tiger snakes were introduced from the mainland around 1920 (Cann, 1986; Aubret et al., 2004b), and Trefoil Island snakes were introduced from mainland Tasmania around 40 years ago (Brothers et al., 2001; Terauds, 2005). 
Table 1 Current and estimated body size, rates of evolution and prey body mass in mainland and island Tiger snake populations ${ }^{\mathrm{a}}$

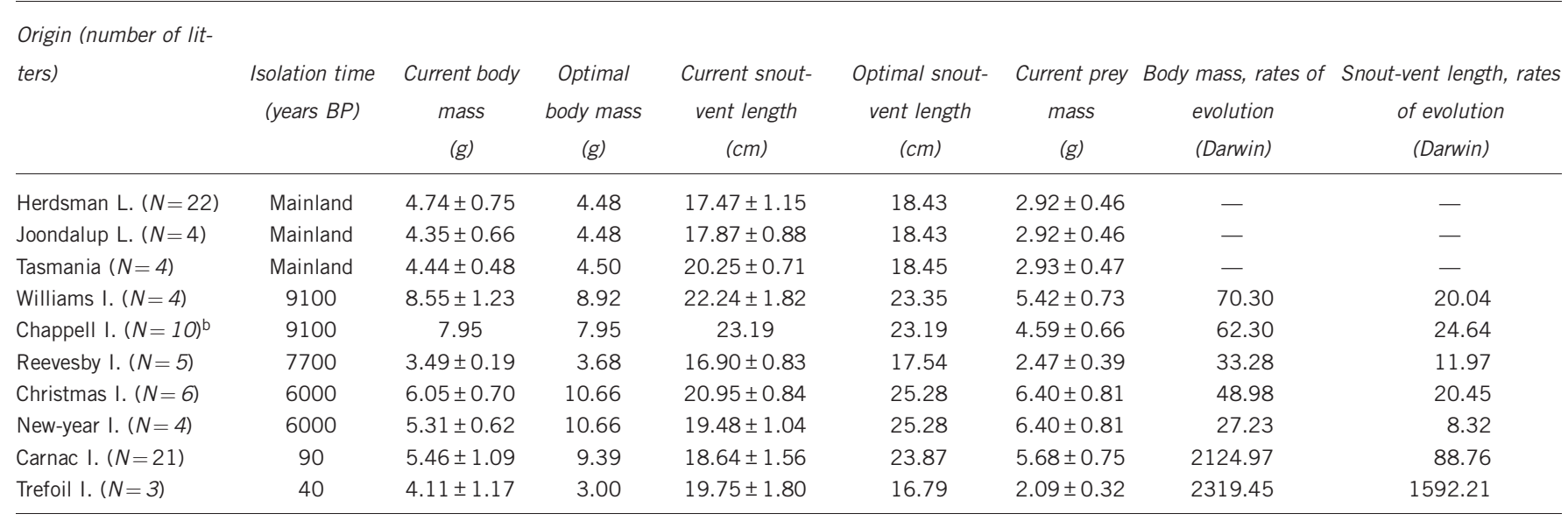

Abbreviation: BP, before present.

a Optimal body mass and snout-vent length were estimated using regression equations drawn from the close relationship between prey body mass and snake body size at birth in mainland and long isolated Tiger snake populations (see text for details). Current prey mass was calculated from detailed measurements of each prey assemblage within each study populations (see Aubret, 2012 for details). Rates of evolution were estimated in Darwins following standard description (Haldane, 1949).

bschwanner and Sarre, 1990.

\section{Current and estimated optimal body size}

Previous published literature suggested that adaptive plasticity cannot be detected in island snakes that have been isolated for $>6000$ years (Aubret and Shine, 2009). Exposing juvenile snakes from these populations to either only small or only large prey did not generate a plastic response in the rates of growth recorded for jaw length or head width over several months, suggesting genetic assimilation of a previously plastic character (Aubret and Shine, 2009). That is, neonate snakes from the same populations were born larger, suggesting that natural selection had fine-tuned snake body size at birth to match prey size (Aubret, 2012). Data from three mainland (Joondalup Lake, Herdsman Lake and mainland Tasmania) and three long isolated populations (Williams Island, Chappell Island, Reevesby Island) were used to perform linear regressions of (1) birth snake body mass and (2) snout-vent length against mean prey mass (see Results). Regression line equations and mean prey sizes were then used to estimate the optimal phenotype for body mass and snoutvent length in four more recently isolated populations (New-Year Island, Christmas Island, Carnac Island and Trefoil Island).

\section{Estimating rates of evolution in body size}

In order to assess current rates of evolution in body size, I first estimated the initial body size of Tiger snakes at the time they were isolated by sea level rise or introduced. Given the absence of reliable data (that is, no fossil record), the most parsimonious assumption is that mainland Tiger snake birth size was comparable at the time of isolation to what it is now. I thus calculated an average body mass and snout-vent length from three mainland populations (Joondalup Lake, $N=63$ neonates; Herdsman Lake, $N=245$; and mainland Tasmania, $N=84$ ). This resulted in an ancestral size of $4.48 \pm 0.16 \mathrm{~g}$ in body mass and $18.49 \pm 1.55 \mathrm{~cm}$ in snout-vent length at birth. For each island population, I then calculated the rates of evolution in body mass and snoutvent length per generation (female Tiger snakes average a litter every 2 years: Shine, 1977; Bonnet et al., 2011; Table 1). The calculation was made as follows: rate of evolution $=($ current body size - ancestral body size $) /($ isolation time $/ 2)$.

Because prey assemblages are not identical across islands, the selective pressure for swallowing abilities may also vary (Aubret and Shine, 2010; Aubret, 2012) and thus directly influence the rates of evolution for snake body size at birth. Variation in food source is indeed one of the most common reasons for rapid body size shifts (Reznick and Ghalambor, 2001). This prompted the use of a rate of evolution index that accounted for this alleged selective pressure. Again, I assumed that the current prey size on the mainland reflected the ancestral mainland prey size at the time of island colonisation. I therefore calculated the difference between the ancestral mean prey size on the mainland $(2.92 \pm 0.46 \mathrm{~g}$; averaged across three mainland populations, as before $)$ and the current mean prey size on each island (Table 1). A body size rate of evolution index was then calculated as: rate of evolution index $=$ rate of evolution/ (current prey size -ancestral prey size), for body mass and snout-vent length.

\section{RESULTS}

Current and estimated optimal body size

Linear regression of birth snake body mass against mean prey mass in three mainland (Joondalup Lake, Herdsman Lake and mainland Tasmania) and three long isolated populations (Williams Island, Chappell Island, Reevesby Island) yielded $N=6 ; R^{2}=0.98$; $\mathrm{F}_{1,4}=170.04 ; P<0.00020$ (Figure 1a) and snake snout-vent length at birth against mean prey mass yielded $N=6 ; R^{2}=0.77$; $\mathrm{F}_{1,4}=12.96 ; \quad P<0.023$ (Figure $1 \mathrm{~b}$ ). Regression line equations $(y=-0.7147+1.7780 x$ for body mass; $y=12.6701+1.9707 x$ for snout-vent length) and mean available prey sizes were used to calculate the optimal phenotype for body mass and snout-vent length in four more recently isolated populations (New-Year Island, Christmas Island, Carnac Island and Trefoil Island). Estimates for optimal body size are given in Table 1 .

\section{Estimating rates of evolution in body size}

Linear regressions of (1) body mass rate of evolution per generation against isolation time yielded $R^{2}=0.91 ; \mathrm{F}_{1,5}=46.44 ; P<0.0010$; and (2) snout-vent length rates of evolution per generation against isolation time yielded $R^{2}=0.77 ; \mathrm{F}_{1,5}=17.90 ; P<0.0082$. Both rates of evolution decreased with isolation time, ranging from 0.021 to $0.00026 \mathrm{~g}$ per generation and from 0.061 to $0.00032 \mathrm{~cm}$ per generation. Taking into account the difference in prey size on each island with the ancestral prey size (that is, reflecting selective pressure to achieve a shift in snake body size towards an optimal body size-see Methods) yielded similar results: inverse first-order regressions provided the best fits of (1) body mass rate of evolution index against isolation time; $R^{2}=0.98 ; \mathrm{F}_{1,5}=299.85 ; P<0.0001$; Akaike's Information Criteria (AIC) $=-20.47$; (Figure 2a) and (2) snout-vent length rate of evolution index against isolation time; $R^{2}=0.83$; $\mathrm{F}_{1,5}=23.89 ; P<0.0045 ; \mathrm{AIC}=-15.26$; (Figure 2b).

\section{Rates of evolution and plasticity levels}

Level of plasticity for head growth in response to prey size calculated experimentally for five island populations in a former 

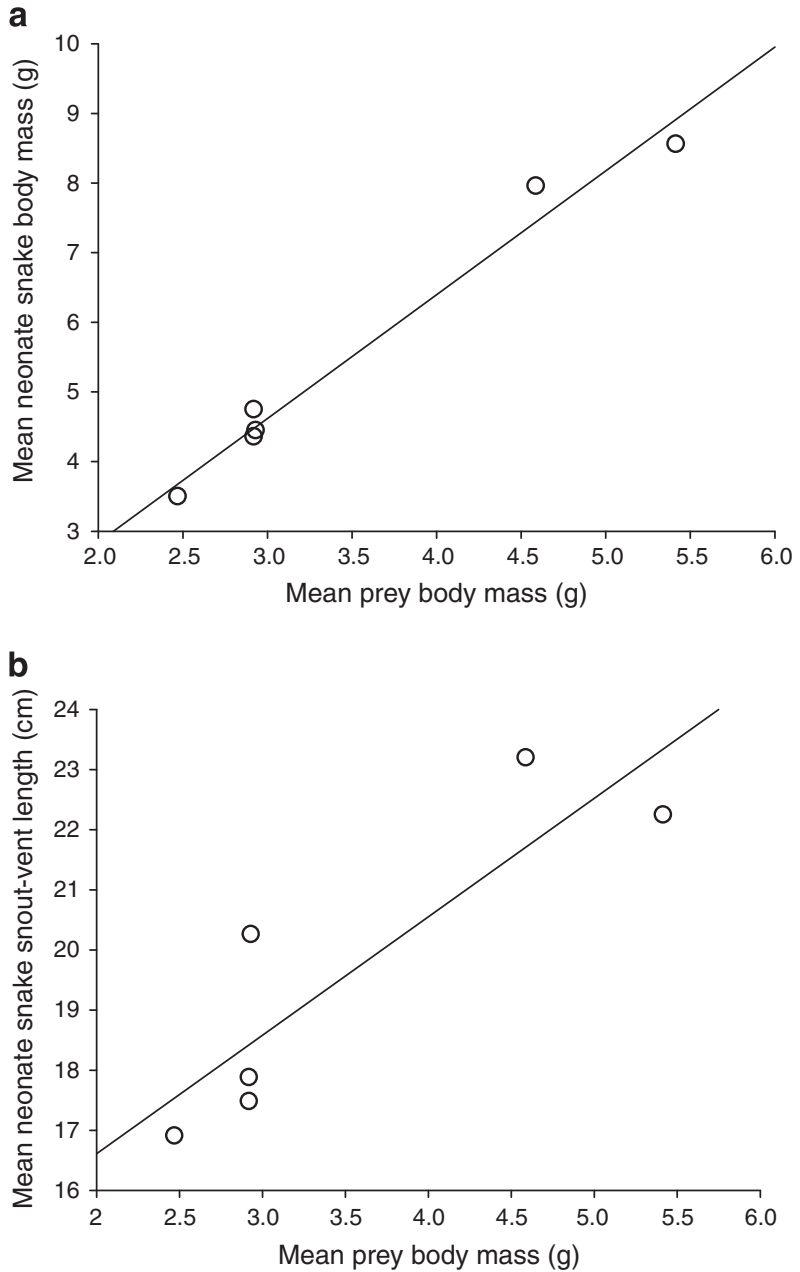

Figure 1 Correlation between mean prey mass and snake body mass at birth (a) and between mean prey mass and snake birth snout-vent length in long isolated and mainland Tiger snake populations. Linear regression of birth snake body mass against mean prey mass yielded $N=6 ; R^{2}=0.98$; $F_{1,4}=170.04 ; P<0.00020$. Linear regression of birth snake snout-vent length against mean prey mass yielded $N=6 ; R^{2}=0.77 ; F_{1}, 4=12.96$; $P<0.023$ (b).

study (Trefoil, Carnac, Christmas, New-year and Williams Islands; Aubret and Shine, 2009) were used as a potential predictor for rates of evolution. Plasticity level significantly correlated with rates of body mass evolution (linear regression; $R^{2}=0.88 ; \mathrm{F}_{1,3}=21.14 ; P<0.019$; Figure 3 ) but not snout-vent length (linear regression; $R^{2}=0.44$; $\left.\mathrm{F}_{1,3}=2.39 ; P<0.22\right)$.

\section{DISCUSSION}

Unusually sized prey can generate an extremely powerful selective pressure on island colonisers (Price et al., 2003; Yeh and Price, 2004; Borenstein et al., 2006). Several authors have pointed out the intimate relationship linking prey availability with mean adult body size in island and mainland Tiger snakes (Schwaner, 1985; Shine, 1987; Keogh et al., 2005). Variation in body size at birth has surprisingly attracted much less attention (Aubret, 2012). Arguably though, population establishment would almost entirely depend on neonates born during the few first reproductive events following geographic isolation. In gape-limited predators, swallowing success is indeed a necessary condition to neonate snake survival (Aubret and Shine, 2010; Aubret, 2012). Mainland Tiger snakes typically produce litters
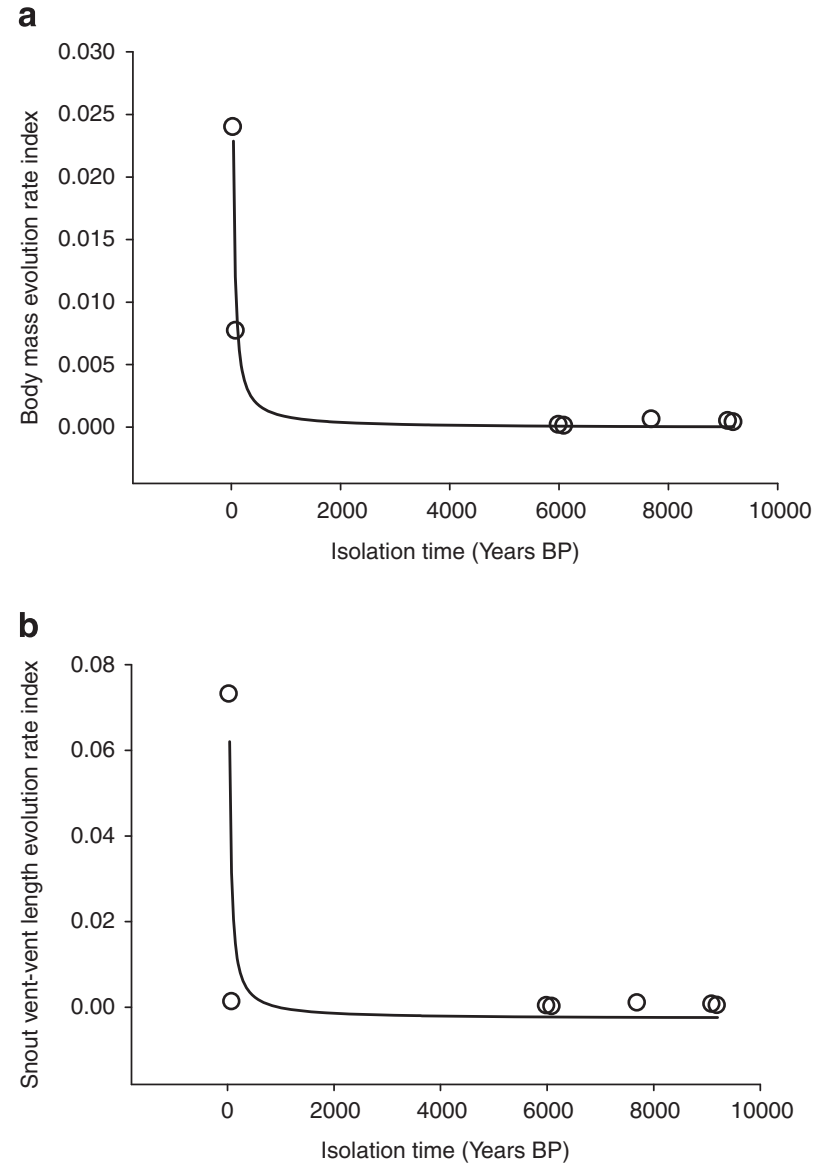

Figure 2 Body size rates of evolution as a function of isolation time. Inverse first-order regressions provided the best fits of (1) body mass rate of evolution index against isolation time yielded $R^{2}=0.98 ; \mathrm{F}_{1,5}=299.85$; $P<0.0001 ; A I C=-20.47 ;$ (a) and (2) snout-vent length rates of evolution index against isolation time yielded $R^{2}=0.83 ; F_{1,5}=23.89 ; P<0.0045$; $\mathrm{AIC}=-15.26$ (b).

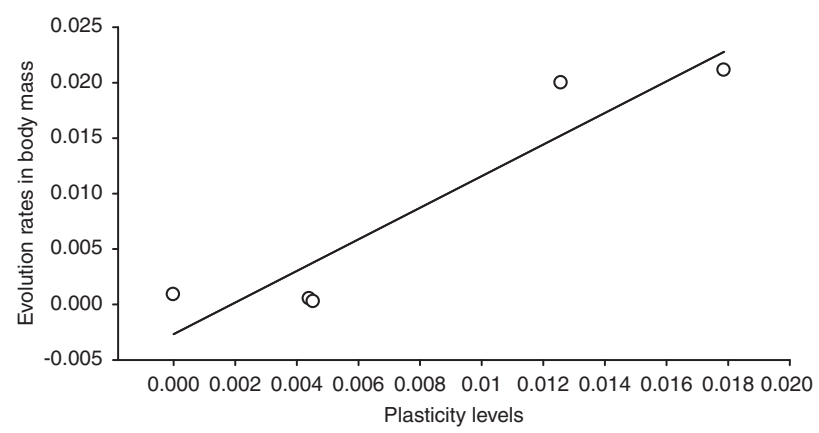

Figure 3 Body mass rates of evolution and levels of adaptive plasticity. Rates of evolution in body mass in grams per generation were significantly correlated with the level of plasticity for head growth in response to prey size calculated for five island populations (linear regression; $R^{2}=0.88$; $\left.\mathrm{F}_{1,3}=21.14 ; P<0.019\right)$.

composed of numerous small neonates that feed on a wide range of small prey items (Aubret, 2012). Insularity created a potentially huge mismatch between prey size and neonate swallowing ability (that is, due to drastically different prey assemblages), generating intense selective pressure for an increase in body and head size of neonate snakes (Forsman, 1991; King, 2002; Aubret et al., 2004a; Aubret and 
a

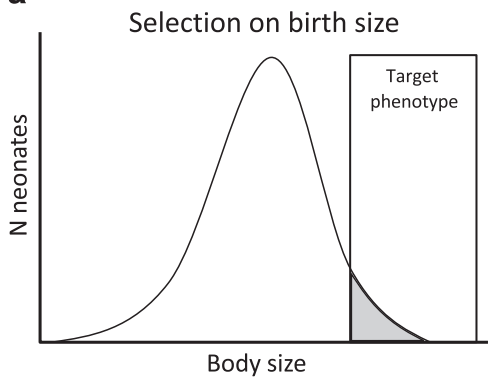

C

b
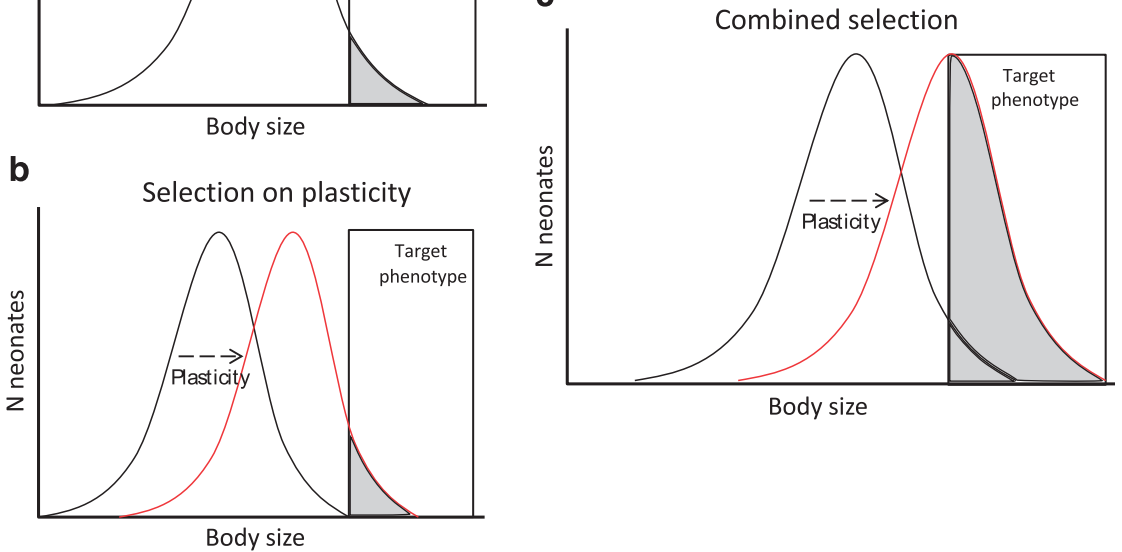

Body size

Figure 4 Putative selection regimes on snake neonate body size are presented upon three alternative scenarios in the early stages of island colonisation. The distribution of snake neonate body size is plotted where target phenotypes are positively selected. Selection towards an optimal phenotype acts on neonate body size (a) and neonate's levels of plasticity in growth rates (b). The combined selective regimes may result in accelerated evolution towards the optimal phenotype (c).

Shine, 2010). In the early stages of colonisation, adaptive plasticity in head growth rates may have provided an advantage to young snakes, where larger prey size stimulated a shift in relative head size as well as body size (that is, as a consequence of enhanced feeding successAubret et al., 2004a; Aubret and Shine, 2009).

As prey size drove the evolution of snake body size at birth (Aubret, 2012), I expected a clear match between prey size available and snake body size in long isolated populations as well as mainland snake populations. This prediction was confirmed by the current study for both mass and snout-vent length at birth. Regression line equations were used to calculate optimal snake body size in four recently colonised islands, based on the current prey assemblages available on each of these islands (Aubret, 2012): estimates (up to $10.66 \mathrm{~g}$ and $25.28 \mathrm{~cm}$ snout-vent length) fell well within the observed body size of neonate Tiger snakes across their natural range (Table 1). As a matter of comparison, giant Tiger snakes found today on Williams Island (9100 years old) give birth to neonates that average $9 \mathrm{~g}$ and $22 \mathrm{~cm}$ in snout-vent length. However, the largest Williams Island laboratoryborn snake measured $11.0 \mathrm{~g}$ and $26.0 \mathrm{~cm}$ snout-vent length (pers. obs).

Rates of evolution in body mass and snout-vent length per generation were both significantly correlated with isolation time. Rate of evolution indexes, which accounted for the main alleged selective pressure at work (prey body mass), yielded similar results (Figure 2). Best-fit regression analysis (both $R^{2}>0.83$ ) further suggested a rather rapid initial adaptive stage followed by decreasing rates of evolution. Remarkably, rates of evolution for body mass also correlated with the level of plasticity in head growth rates experimentally recorded in each snake population in a former study using independent data (Aubret and Shine, 2009). Could adaptive plasticity be responsible for faster rates of evolution observed in 'young' island snake populations, as suggested by the theoretical work (Ancel, 2000; Ghalambor et al., 2007; Lande, 2009)?

Putative selection regimes generated by large prey size on neonate body size in the early stages of island colonisation are presented in
Figure 4. Because swallowing performances are strongly dependent on body and head size, only the very largest of snakes within a cohort might be able to acquire a first meal before they starve to death (Figure 4a; King, 2002; Aubret and Shine, 2010). On the other hand, snakes capable of quickly increasing their rate of growth in jaw size in response to large prey items will have access to a wider variety of prey sizes and will have improved survival (Figure 4b; Aubret and Shine, 2009, 2010). As such, scenario B is a classic case of adaptive plasticity allowing the successful colonisation of novel environments, generating a rapid shift in plasticity levels in the population (Ehrlich, 1989; Holway and Suarez, 1999; West-Eberhard, 2003; Yeh and Price, 2004; Fitzpatrick, 2012). A third possibility exists, however, in the form of combined selection for swallowing performance. That is, some neonate snakes will happen to be among the largest within their cohort as well as the most plastic. The fitness advantages of simultaneously possessing both attributes (a large body size as well as high levels of plasticity) likely add up (Figure 4c) and thus impart greater advantages than the fitness advantages of possessing only one or the other trait (Figures $4 \mathrm{a}$ and b). Swallowing performances and body size are indeed linked by a positive feed-back loop that accelerates growth towards sexual maturity (Forsman, 1996; King, 2002; Aubret and Shine, 2007, 2010; Vincent and Mori, 2008). The larger a snake grows, the larger the prey items it can ingest. Faster-growing snakes are likely to attain sexual maturity earlier (or at a larger body size) and increase litter or egg size (Ford and Seigel, 1989; Beaupre et al., 1998; Rivas and Burghardt, 2001). Accelerated growth may also increase survival rate by reducing vulnerability to predation (risk of predation in reptiles is size dependent; Ferguson and Fox, 1984; Forsman, 1993; Webb and Whiting, 2005). Consequently, such individuals may rapidly prevail in the colonising population. As such, the evolutionary effect of such combined selection would resemble an evolutionary bottleneck, with accelerated rates of evolution towards an optimal phenotype. 
As the phenotype approaches the optimal value, however, fitness costs and limits of plasticity may start to lower fitness and lead to the evolutionary replacement of the plastic solution by a canalised solution (Pigliucci et al., 2006; Aubret and Shine, 2010). These ideas are related to the concept of genetic assimilation first described by Waddington (1942, 1961) and Schmalhausen (1949). Adaptive plasticity may provide a selective advantage in the early stages of the colonising event, but a consistent selective force for larger head size ultimately will result in the replacement of the plasticity-based pathway with a canalised genetic basis for the trait (Pigliucci and Murren, 2003; Pigliucci et al., 2006; Aubret and Shine, 2009; Lande, 2009). This is supported by two experimental studies that demonstrated (1) a progressive replacement of plasticity in head growth by large head size at birth along the colonisation timeframe in island Tiger snakes (Aubret and Shine, 2009) and (2) that developmental plasticity conferred a fitness cost in terms of growth rates in young Tiger snakes (Aubret and Shine, 2010). Ultimately, plastic phenotypes may be out competed by canalised phenotypes (Pigliucci et al., 2006; Aubret and Shine, 2010). As the additive effect of adaptive plasticity on rates of evolution is lost, evolution may slow down (Figure 2).

There are potential limitations to the validity of such an evolutionary scenario, however. First, gene flow between island and mainland, as well as between nearby islands could potentially confound the results (Lind et al., 2011). The genetic study by Keogh et al. (2005) showed that body size shifts had evolved independently across island populations of Tiger snakes. However, Keogh et al. (2005) did not look at gene flow per se. In the absence of specific studies, one can only rely on direct observations. To my knowledge, island Tiger snakes do not swim in the ocean. Winds and currents are usually strong around islands off southern Australia and would render a journey from the mainland to an island or between islands, deliberate or not, very uncertain. Such an event, if successful, would be extremely rare. Gene flow is thus, if not nil, most likely negligible in its impact on the evolution of body size in snake populations made by several hundred individuals (Bonnet et al., 2002). More importantly, the idea of an optimal phenotype remaining optimal over a lengthy period of evolutionary time is more debatable, however. In birds, it was shown that the optimal beak phenotype varies from year to year, depending on the seed type available in relation to rainfall (Grant and Grant, 2002). In this case, beak phenotypes are at best temporally optimal phenotypes. Can a similar case be made for island Tiger snakes? There is limited data available in the literature with respect to yearly variation in prey assemblage on each island. Bonnet et al. (1999, 2002), however, have gathered extensive longterm data on the Carnac Island snake population since 1997, as part of a mark-recapture study. The island snake population is surveyed every spring (but not exactly at the same time), and prey occurring on site or regurgitated by snakes upon capture are identified. No obvious variation in prey types, densities or prey specifically taken by the snakes has so far been reported. In the current study, prey sampling occurred as a by-product of snake collection, during which pregnant females were captured and flown back to the laboratory. Hence, even if variations in prey availability and their corresponding optimal snake phenotypes occur, the data presented in this manuscript match prey assemblage with current snake phenotype. Another argument may be put forward: a case of ever changing prey availability (prey type, prey size) would be a perfect selective force for the maintenance of a high level of adaptive plasticity in head growth rates in island snakes (Lynch and
Gabriel, 1987; Gomulkiewicz and Kirkpatrick, 1992). On the contrary, plasticity levels were shown to decrease as a function of isolation time (Aubret and Shine, 2009), suggesting that island environments are rather stable in their fauna composition (Rawlinson, 1974; Robinson et al., 1996).

Although previously supported by mathematical models (Belew and Mitchell, 1996; Ancel, 2000; Ghalambor et al., 2007; Lande, 2009), the idea that adaptive plasticity can speed up evolution towards an optimal phenotype (that is, Baldwin effect; Ancel, 2000) has received little empirical support (Anderson et al., 2012). This study showed that rates of evolution in body mass in island snakes were correlated with (1) isolation time, and (2) levels of plasticity for head growth rates. As such, and despite small sample sizes and the statistical limitations inherent with correlative studies (Holland, 1986), this study provides some empirical support for plasticity's hypothesised roles in directing evolutionary trajectories (Simpson, 1953; Ancel, 2000; de Jong, 2005).

\section{DATA ARCHIVING}

Data on snake body size and prey size are available at the Dryad repository: http://dx.doi.org/10.5061/dryad.14cr5345.

\section{CONFLICT OF INTEREST}

The author declares no conflict of interest.

\section{ACKNOWLEDGEMENTS}

Funding was provided by the University of Western Australia, the Région Poitou-Charentes, the Australian Research Council (ARC), and the Centre National de la Recherche Scientifique (CNRS). I wish to thank W Gigg, D Roberts, D Bradshaw, X Bonnet, D Pearson, J Thomas, R Shine, M Elphick, $\mathrm{R}$ Michniewicz, as well as numerous and diverse helpers throughout the years of collection of these data. I wish to express my gratitude to the owners of Trefoil Island for granting special access to this Aboriginal land and Dr Mark Hutchinson for allowing me access to the snake collections. I also thank Léa Aubret, Camille Bonneaud, Alexis Chaine and Virginie Stevens for their helpful comments on the manuscript. This work is part of the LABEX entitled TULIP (ANR-10-LABX-41).

Ancel LW (2000). Undermining the Baldwin expediting effect: does phenotypic plasticity accelerate evolution. Theor Popul Biol 58: 307-319.

Anderson JT, Inouye DW, McKinney AM, Colautti RI, Mitchell-Olds T (2012). Phenotypic plasticity and adaptive evolution contribute to advancing flowering phenology in response to climate change. Proc $R$ Soc Lond B Biol 279: 3843-3852.

Arena PC, Wooller RD (2003). The reproduction and diet of Egernia kingii (Reptilia: Scincidae) on Penguin Island, Western Australia. Aust J Zool 51: 495-504.

Aubret F (2012). Body size evolution on islands: are adult size variations in Tige snakes a non-adaptive consequence of selection on birth size? Am Nat 179 756-767.

Aubret F, Bonnet X, Maumelat S, Bradshaw SD, Schwaner T (2004b). Diet divergence, jaw size and scale counts in two neighbouring populations of Tiger snakes (Notechis scutatus). Amphibia Reptilia 25: 9-17.

Aubret F, Shine R (2007). Rapid prey-induced shift in body size in an isolated snake population (Notechis scutatus, Elapidae). Austral Ecol 32: 889-899.

Aubret F, Shine R (2009). Genetic assimilation and the post-colonization erosion of phenotypic plasticity in island Tiger snakes. Curr Biol 19: 1932-1936.

Aubret F, Shine R (2010). Fitness costs may explain the post-colonization erosion of phenotypic plasticity. J Exp Biol 213: 735-739.

Aubret F, Shine R, Bonnet X (2004a). Adaptive developmental plasticity in snakes. Nature 431: 261-262.

Badyaev AV (2005). Stress-induced variation in evolution: from behavioural plasticity to genetic assimilation. Proc R Soc Lond B Biol 272: 877-886.

Beaupre SJ, Duvall D, O'Leile J (1998). Ontogenetic variation in growth and sexual size dimorphism in a central Arizona population of the western diamondback rattlesnake (Crotalus atrox). Copeia 1998: 40-47.

Behera N (1994). Phenotypic plasticity and genetic assimilation in development and evolution. Bionature 14: 1-22.

Belew RK, Mitchell M (1996). Adaptive Individuals in Evolving Populations: Models and Algorithms. Addison-Wesley: Reading, MA, USA. 
Belperio AP, Hailsand JR, Gostin VA (1983). A review of Holocene sea levels in South Australia. In: Hopley D (ed). Australian Sea Levels in the Last 15000 Years: A Review. Monograph Series Occasional Paper, James Cook University of North Queensland: Townsville, Australia, pp 37-47.

Boback SM (2003). Body size evolution in snakes: evidence from island populations. Copeia 2003: 81-94.

Bonnet X, Bradshaw SD, Shine R, Pearson D (1999). Why do snakes have eyes? The (non-) effect of blindness in island Tiger snakes. Behav Ecol Sociobiol 46: 267-272.

Bonnet X, Lorioux S, Pearson D, Aubret F, Bradshaw D, Delmas V et al. (2011). Which proximate factor determines sexual size dimorphism in Tiger snakes? Biol J Linn Soc 103: 668-680.

Bonnet X, Pearson D, Ladyman M, Lourdais O, Bradshaw SD (2002). 'Heaven' for serpents? A mark-recapture study of Tiger snakes (Notechis scutatus) on Carnac Island, Western Australia. Austral Ecol 27: 442-450.

Borenstein E, Meilijson I, Ruppin E (2006). The effect of phenotypic plasticity on evolution in multipeaked fitness landscapes. J Evol Biol 19: 1555-1570.

Brothers N, Pemberton D, Pryor H, Halley V (2001). Tasmania's Offshore Islands: Seabirds and Other Natural Features. Tasmanian Museum and Art Gallery: Hobart, Australia.

Cann J (1986). Snakes Alive. Kangaroo Press: Sydney, Australia.

Case TJ (1978). A general explanation for insular body size trends in terrestrial vertebrates. Ecology 59: 1-18.

Chapple DG (2005). Life-history and reproductive ecology of White's Skink Egernia whitii. Aust J Zool 53: 353-360.

Cogger HG (2000). Reptiles and Amphibians of Australia, 6th edn. Reed New Holland: Sydney, Australia.

Darwin C (1845). Journal of Researches into the Natural History and Geology of the Countries Visited During the Voyage of H.M.S. Beagle Round the World, Under the Command of Capt. Fitz Roy, RA, 2nd edn. John Murray: London, UK.

de Jong G (2005). Evolution of phenotypic plasticity: patterns of plasticity and the emergence of ecotypes. New Phytol 166: 101-118.

Ehrlich PR (1989). Attributes of invaders and the invading process: vertebrates. In: Drake JA et al. (eds). Biological Invasions: a Global Perspective. Wiley and Sons: Chichester, UK, pp 315-328.

Ferguson GW, Fox SF (1984). Annual variation of survival advantage of large juvenile sideblotched lizards, Uta stansburiana: its causes and evolutionary significance. Evolution 38: 342-349.

Fitzpatrick BM (2012). Underappreciated consequences of phenotypic plasticity for ecological speciation. Int J Ecol 2012: 256017

Ford NB, Seigel RA (1989). Relationships among body size, clutch size, and egg size in three species of oviparous snakes. Herpetologica 45: 75-83.

Forsman A (1991). Adaptive variation in head size in Vipera berus L. populations. Biol J Linn Soc 43: 281-296.

Forsman A (1993). Survival in relation to body size and growth rate in the adder Vipera berus. J Anim Ecol 62: 647-655.

Forsman A (1996). Body size and net energy gain in gape-limited predators: a model. $J$ Herpetol 30: 307-319.

Foster JB (1964). Evolution of mammals on islands. Nature 202: 234-235.

Garcia-Porta J, Ord TJ (2013). Key innovations and island colonization as engines of evolutionary diversification: a comparative test with the Australasian diplodactyloid geckos. J Evol Biol 26: 2662-2680.

Gavrilets S, Vose A (2005). Dynamic patterns of adaptive radiation. Proc Natl Acad Sci USA 102: 18040-18045.

Ghalambor CK, McKay JK, Carrol SP, Reznick DN (2007). Adaptive versus non-adaptive phenotypic plasticity and the potential for contemporary adaptation in new environments. Funct Ecol 21: 394-407.

Gomulkiewicz R, Kirkpatrick M (1992). Quantitative genetics and the evolution of reaction norms. Evolution 46: 390-411.

Grant PR (1999). The Ecology and Evolution of Darwin's Finches. Princeton University Press: Princeton, NJ, USA.

Grant PR, Grant BR (2002). Unpredictable evolution in a 30-year study of Darwin's finches. Science 296: 707-711.

Grant PR, Grant BR (2006). Evolution of character displacement in Darwin's finches. Science 313: 224-226.

Haldane JBS (1949). Suggestions as to quantitative measurement of rates of evolution. Evolution 3: 51-56.

Herrel A, Huyghe K, Vanhooydonck B, Backeljau T, Breugelmans K, Grbac I et al. (2008). Rapid large-scale evolutionary divergence in morphology and performance associated with exploitation of a different dietary resource. Proc Natl Acad Sci USA 105 4792-4795.

Hinton GE, Nowlan SJ (1987). How learning can guide evolution. Complex Syst 1: 495-502.

Holland PW (1986). Statistics and causal inference. J Am Stat Assoc 81: 945-960.

Holway DA, Suarez AV (1999). Animal behavior: an essential component of invasion biology. Trends Ecol Evol 14: 328-330.

Keogh JS, Scott IA, Hayes C (2005). Rapid and repeated origin of insular gigantism and dwarfism in Australian Tiger snakes. Evolution 59: 226-233.

King RB (2002). Predicted and observed maximum prey size— - snake size allometry. Funct Ecol 16: 766-772.

Lambeck K, Chappell J (2001). Sea level change through the last glacial cycle. Science 292: 679-686.

Lande R (2009). Adaptation to an extraordinary environment by evolution of phenotypic plasticity and genetic assimilation. J Evol Biol 22: 1435-1446.
Lind MI, Ingvarsson PK, Johansson H, Hall W, Johansson F (2011). Gene flow and selection on phenotypic plasticity in an island system of Rana temporaria. Evolution 65: 684-697.

Lomolino MV (1985). Body size of mammals on islands: the island rule re-examined. Am Nat 125: 310-316.

Losos JB, Ricklefs RE (2009). Adaptation and diversification on islands. Nature 457: 830-836.

Lynch M, Gabriel W (1987). Environmental tolerance. Am Nat 129: 283-303.

Mathys BA, Lockwood JL (2011). Contemporary morphological diversification of passerine birds introduced to the Hawaiian archipelago. Philos Trans $R$ Soc Lond $B$ 278: 2392-2400.

Mayley G (1996). Landscapes, learning costs, and genetic assimilation. Evolut Comput 4: 213-234.

Meiri S (2007). Size evolution in island lizard. Global Ecol Biogeogr 16: 702-708.

Meiri S, Cooper N, Purvis A (2008). The island rule: made to be broken? Proc Roy Soc Lond B 275: 141-148.

Meiri S, Dayan T, Simberloff D (2006). The generality of the island rule re-examined. J Biogeogr 33: 1571-1577.

Millien V (2006). Morphological evolution is accelerated among island mammals. PLoS Biol 4: 1863-1868.

Pigliucci M, Murren CJ (2003). Perspective: genetic assimilation and a possible evolutionary paradox: can macroevolution sometimes be so fast as to pass us by? Evolution 57: 1455-1464.

Pigliucci M, Murren CJ, Schlichting CD (2006). Phenotypic plasticity and evolution by genetic assimilation. J Exp Biol 209: 2362-2367.

Price TD, Qvarnström A, Irwin DE (2003). The role of phenotypic plasticity in driving genetic evolution. Proc Roy Soc Lond B Bio 270: 1433-1440.

Rawlinson PA (1974). Biogeography and ecology of the reptiles of Tasmania and the Bass Strait area. In: Williams ED (ed). Biogeography and Ecology in Tasmania. Junk: The Hague, Netherlands, pp 291-338.

Relyea RA (2002). Costs of phenotypic plasticity. Am Nat 159: 272-282.

Reznick DN, Ghalambor CK (2001). The population ecology of contemporary adaptations: what empirical studies reveal about the conditions that promote adaptive evolution. Genetica 112-113: 183-198.

Rivas JA, Burghardt GM (2001). Understanding sexual size dimorphism in snakes: wearing the snake's shoes. Anim Behav 62: F1-F6.

Robinson T, Canty P, Mooney T, Ruddock P (1996). South Australia's Offshore Islands. Australian Heritage Commission: Canberra, Australia.

Rollo CD (1994). Phenotypes: Their Epigenetics, Ecology and Evolution. Chapman and Hall: London, UK

Schlichting CD (2004). The role of phenotypic plasticity in diversification. In: DeWitt TJ, Scheiner SM (eds). Phenotypic Plasticity: Functional and Conceptual Approaches. Oxford University Press: Oxford, UK, pp 191-200.

Schlichting CD, Pigliucci M (1998). Phenotypic Evolution: A Reaction Norm Perspective. Sinauer Associates: Sunderland, MA, USA.

Schmalhausen II (1949). Factors of Evolution. Blakiston: Philadelphia, PA.

Schwaner TD (1985). Population structure of black Tiger snakes, Notechis ater niger, on off-shore islands of South Australia. In: Grigg G, Shine R, Ehmann H (eds). Biology of Australasian frogs and reptiles. Surrey Beatty and Sons: Sydney, Australia, pp 35-46.

Schwaner TD, Sarre SD (1988). Body size of Tiger snakes in Southern Australia, with particular reference to Notechis ater serventyi (Elapidae) on Chappell Island. J Herpetol 22: 24-33.

Schwaner TD, Sarre SD (1990). Body size and sexual dimorphism in mainland and island Tiger snakes. J Herpetol 24: 320-322.

Scott AW, Hayes C, Keogh JS, Webb JK (2001). Isolation and characterization of novel microsatellite markers from the Australian Tiger snakes (Elapidae: Notechis) and amplification in the closely related genus Hoplocephalus. Mol Ecol Notes 1: $117-119$.

Shine R (1977). Reproduction in Australian elapid snakes II. Female reproductive cycles. Aust J Zool 25: 655-666

Shine R (1987). Ecological comparisons of island and mainland populations of Australian tigersnakes (Notechis: Elapidae). Herpetologica 43: 233-240.

Simpson GG (1953). The Baldwin effect. Evolution 7: 110-117.

Snell-Rood EC, Van Dyken JD, Cruickshank T, Wade MJ, Moczek AP (2010). Toward a population genetic framework of developmental evolution: the costs, limits, and consequences of phenotypic plasticity. Bioessays 32: 71-81.

Stearns SC (1989). The evolutionary significance of phenotypic plasticity. BioScience 39 : 436-445.

Steinger T, Roy BA, Stanton ML (2003). Evolution in stressful environments ii: adaptive value and costs of plasticity in response to low light in Sinapis arvensis. J Evol Biol 16: 313-323.

Swain R, Jones SM (2000). Maternal effects associated with gestation conditions in a viviparous lizard Niveoscincus metallicus. Herpetol Monogr 14: 432-440.

Terauds A (2005). Introduced Animals on Tasmanian Islands. Department of Primary Industries, Water and Environment: Hobart, Australia.

Thom BG, Chappell J (1975). Holocene sea levels relative to Australia. Search 6: 90-93. Via S, Gomulkiewicz R, De Jong G, Scheiner SM, Schlichting CD, Van Tienderen PH (1995). Adaptive phenotypic plasticity: consensus and controversy. Trends Ecol Evol 10: 212-217.

Vincent SE, Mori A (2008). Determinants of feeding performance in free-ranging pit-vipers (Viperidae: Ovophis okinavensis): key roles for head size and body temperature. Biol J Linn Soc 93: 53-62. 
Waddington $\mathrm{CH}$ (1942). Canalization of development and the inheritance of acquired characters. Nature 150: 563-565.

Waddington $\mathrm{CH}$ (1953). Genetic assimilation of an acquired character. Evolution 7 118-126.

Waddington CH (1961). Genetic assimilation. Adv Genet 10: 257-293.

Webb JK, Whiting MJ (2005). Why don't small snakes bask? Juvenile broad-headed snakes trade thermal benefits for safety. Oikos 110: 515-522.
West-Eberhard MJ (2003). Developmental Plasticity and Evolution. Oxford University Press: Oxford, UK.

Wilson S, Swan G (2003). A Complete Guide to Reptiles of Australia. New Holland Publishers: Sydney, Australia.

Worrell E (1963). Reptiles of Australia. Angus and Robertson: Sydney, Australia.

Yeh PJ, Price TD (2004). Adaptive phenotypic plasticity and the successful colonization of a novel environment. Am Nat 164: 531-542. 